\title{
Pesticides Residue in Milk and Milk Products: Mini Review
}

\author{
Shazia Akhtar*1 and Karam Ahad ${ }^{2}$ \\ ${ }^{1 *}$ Ecotoxicology Research Institute, NARC, Islamabad, Pakistan. \\ ${ }^{2}$ Ecotoxicology Research Institute, NARC, Islamabad, Pakistan. \\ *Corresponding author E-mail: shazoo_786@yahoo.com \\ Received 10 September 2016, Revised 14 June 2017, Accepted 23 June 2017
}

\begin{abstract}
Livestock is an important sub-sector of agriculture that plays a key role in economy of a country by contributing to GDP (Gross Domestic Product) and in total export. Pakistan is the $5^{\text {th }}$ largest milk producer in the world with a total milk production of about 46.44 billion liters per anum. Almost $68 \%$ milk is produced by buffalo and $27 \%$ by cow. Pesticides used in agriculture sector may transfer to animal bodies through feed and fodder. A pesticide found in water is another source of residues in milk through drinking water. External control of parasites on animal body, insect control in cattle yard and sheds are direct sources of pesticides exposure for dairy animals. Due to its nutritional and supplementary value, milk is being consumed by people of different age groups therefore, issue of pesticide residues attain the immediate attention of researcher. Pesticide residues levels in raw dairy milk are discussed here in few selected developing and developed countries. It is concluded that human health is associated with exposure to organo phosphorus (OPPs), organo chlorine pesticide (OCPs), pyrethroids and carbamate (CB) pesticides via milk or milk products and this issue deserve more attention. Different classes of pesticides OPPs, OCPs, pyrethroids and CBs etc. were reported in raw dairy milk in different countries and also in Pakistan. The results of this review demonstrate the need to establish pesticide residue monitoring programs for milk analysis for human consumption to improve food safety and decrease exposure risks to consumers.
\end{abstract}

Keywords: Pesticides residues, Organochlorine pesticide, Organophosphorus pesticide, Milk, Maximum residues levels.

\section{Introduction}

Pakistan is an agricultural developing country. Its economy is mainly based on agriculture and livestock that play an important role. About 30 to 35 million population is involved in livestock. Overall in rural areas every family has cattle, goats and buffalo. From these animals people receive their 30 to $40 \%$ income. Almost $68 \%$ milk is being produced by buffalo, $27 \%$ from cow and $5 \%$ from goat, sheep and camel. Buffalo is main animal contributing to milk production. Pesticides entere in the human body through food, which have animal origin especially richin lipid content rich. Livestock is an important sector in Pakistan [1]. Some studies report that animal origin food is responsible for $90 \%$ pesticides entry in the human body [2]. Milk has nutritional and supplementary value as well as it is being consumed by peoples of different age groups therefore, this issue attain the immediate attention of researcher. Since, milk contains a considerable amount of fat, therefore presence of these lipophilic compounds in it is beyond any suspicion. Presence of pesticides in milk was reported by several authors in different countries over the last few decades, and use of most of these chemicals had been banned in many countries [3].

\section{Sources of pesticide residues in milk}

In agriculture, crops like fruits, vegetables and cereals are treated with different types of synthetic chemicals, which are known as pesticides 
[4]. Pesticides include insecticides, herbicides, rodenticides and fungicides etc. These pesticides are applied pre-harvest, post harvest and storage stages. They have ability to transfer from lower plants and animals to the higher plants and animals among the food chain and can accumulate in the higher organisms [5]. In addition to this, sometimes pesticides are directly sprayed to the animal accommodation to infest the pest [6]. Ultimately, both routes (plants and animals) lead to the bioaccumulation of pesticides in the animal products like milk, meat, fat and eggs. Pesticides source in dietary rout is main way of chronic exposure to these substances $[7,8]$.

\section{Analytical methodologies for pesticide residues}

There are different techniques used for pesticide residues analysis in milk. Gas chromatography (GC) as well as liquid chromatography (LC) is being used as separation technique coupled with some detectors. Ideal detectors used for the detection and quantification of pesticide residues would respond only to target analyte, while other coextracted elements remain transparent [9].

Gas chromatography has been used with different detectors like electron capture detector (ECD), micro- ECD ( $\mu$-ECD), GC-NPD (nitrogen phosphorus detector) and Flame ionization detector (FID). Mass spectrometric detector (MSD) is termed as the universal detector on the basis of its non-specific properties. MSD being versatile and selective detector is preferred by analyst [10].

LC-MS and LC-MS/MS is an ideal, extremely specific and highly sensitive technique used for identification and quantification of pesticide residues. It provides information about analyte without derivatizing. It can compensate sample purity and it enables simultaneous analysis of the compounds with varying polarity [11].

\section{Public health concerns}

A wide range of milk and milk products are consumed by the peoples of all ages. From polluted grass, corn, silage and through pesticides direct application on cattle, these chemicals accumulate in the cattle milk. As humans beings are on the top of tropic level or in the food chain, they are bigger consumers of pesticides. Products of animal origin: meat, fish, eggs and especially dairy products are main source of OCPs and OPPs intake in general public [12]. These pesticides cause a wide range of toxic effects and pose very severe health risks, specifically in infants, who have less developed metabolic and enzymatic systems [13]. Overall health effects on humans by pesticides are not well defined but evidences are increasing for genotoxicity, carcinogenity and hormonal disturbance $[14,15]$.

Milk has been analyzed as an indicator of the bio-concentration for the persistent organic pollutant like pesticides [16]. A class of pesticides, organo chlorine, which are lipophilic and has little metabolism in the body of living animals. Environmental exposure of organo chlorines leads to their accumulation in fats tissues and magnify in living tissues through the food chain [17].

\section{Status of pesticide residues in milk and milk products}

This review covers the level of pesticides contamination in different countries especially in developing countries. In this regard, Pandit [18] monitored milk samples of different brands in Maharashtra, India to check the pesticide residues contamination. Analysis was done with GC technique with $\mu$ ECD. Hexachlorocyclohexane $(\mathrm{HCH})$ and di-chlorodiphenyltri-chloroethane (DDT) were detected in trace amount in milk samples. Overall HCH level was lower than DDT. This may be due to anti-malarial sanitary activities. Results showed that butter have higher concentration of DDT than milk and cheese. However, Organo chlorine pesticides levels were blow the FAO (Food and Agriculture Organization)/ WHO (World Health Organization) standards.

It was investigated in a study, cow and buffalo milk samples were collected from 6 different markets of Menia El-Kamh province of the Sharkia Governorate constitutes, one of the largest agricultural area in the Egypt. Thirteen 
different pesticides were analyzed by High performance liquid chromatography (HPLC) and DDT, Larvin, Anifose and methomyl were detected in milk samples and their concentrations as high as $67 \mu \mathrm{g} / \mathrm{kg}$ (larvin), $88 \mu \mathrm{g} / \mathrm{kg}$ (anilifos), $138 \mu \mathrm{g} / \mathrm{kg}$ (DDT), and $325 \mu \mathrm{g} / \mathrm{kg}$ (methomyl) were found in cow or buffallo milk [19].

Another monitoring study was carried on to check the HCH and DDT. As chemicals are extensively being used in public health and livestock programs in the central tropical region in Mexico. Milk samples were collected from Tlalixcoyan and analyzed HCH and DDT. Results demonstrate the mean level of $\mathrm{HCH}$ was significantly higher than residues in milk samples from Medellin $\left(0.049 \mathrm{mg} / \mathrm{kg}^{-1}\right)$ and Paso San Juan $\left(0.022 \mathrm{mg} / \mathrm{kg}^{-1}\right)$. The DDT mean level from Medellin milk samples $\left(0.089 \mathrm{mg} / \mathrm{kg}^{-1}\right)$ was significantly higher than the levels detected in the other two areas. These results showed that infants are at more risk of exposure to pesticides residues. These findings indicate that those cattle exposed to DDT and $\mathrm{HCH}$ accumulates these chemicals in their milk and may pose health risk to the consumer [20].

Pagliuca et al. [21] described that OPPs, which are being used in agricultural system, they can accumulate in food chain and ultimately pose toxic effects on animals and human beings. In Italy a research was carried out conducted to determine the OPPs in dairy milk and to adopt the special procedure for risk management in the whole milk production chain. Milk samples were collected from tanks trucks of four dairy plants in Italy, which were representations of 920 tons of raw milk. The separation of the 8 OPPs (acephate, chlorpyriphos, chlorpyriphos-methyl, diazinon, methamidophos, methidathion, phorate, pirimiphos-methyl) was done through liquid partition and then clean-up with solid phase extraction. Gas chromatography with Nitrogen phosphorus detector (NPD) was used for detection analysis. Total 135 samples were analyzed and 37 showed positive results and 10 were contaminated with OPPs $(5-18 \mathrm{mg} / \mathrm{kg})$. Acephate and chlorpyriphos was main contaminant. However, OPPs level of contamination was lower than MRLs given by European Commission (EC).
Weber [22] stated that OCPs are not readily degradable and are lipophilic in nature. That is why OCPs have tendency to bioaccumulate in fatty foods like milk. After a long exposure to OCPs adverse type of health effects may develop. Although it is banned in some countries even then its residues are being found and OCPs accumulation in fatty foods is a major concern.

A method was developed for trichlorfon residue as dichlorovos analysis by GC- $\mu$ ECD. Dichlorovos confirmation was done by mass spectroscopy. In this protocol acetonitrile was used for milk extraction then centrifugation followed by freezing and partitioning in dichloromethane. Ethyl acetate was used for dissolution of residues for GC. Average recoveries were noticed from $92.4 \%$ $-103.6 \%$. No any residue was detected in milk samples collected from seven major cities of Korea [23].

During the handling and processing, milk and milk products could be contaminated. Buffalos and cow milk was investigated for pesticides residue in Egypt. OPPs (profenofos, malathio, pirimiphos-methyle and dimethoate) were not detected in any milk sample. However, OCPs (lindane, aldrin, heptachlor, epoxide, HCB, eldrin, chlordane and DDT) were present above the recommended limit established by $\mathrm{FAO} / \mathrm{WHO}$ [13].

Milk and feedstuff of goats and sheep was monitored in a research. Total 200 milk samples were collected from 10 goat and 10 sheep farms. Milk samples were analyzed for 99 multi residues by GC-MS (GC- Mass Spectrometry) and LCMS/MS (LC-Liquid chromatography) systems. Feedstuff samples were contaminated with pesticides residues; however milk, samples were contaminated but found under safe limits [24].

Another study was reported by Karabasanavar \& Singh [25] for public health and plants defense against pest, pesticides are being used. Entrance of these pesticides to the food chain is very harmful. Application of chloropyrifos in the agricultural and associated fields leads to the pesticides accumulation in milk also. A study was 
designed to determine the chloropyrifos concentration in milk. For this purpose milk samples were collected from Kumaon and Tarai of Uttarakhand state. HPLC technique was used to analyze the milk samples. Total 170 samples were analyzed and out of which $4.7 \%$ milk samples were detected with chloropyrifos residues which were also above the MRLs $\left(0.02 \mathrm{mg} / \mathrm{kg}^{-1}\right)$.

It was investigated OCPs in dairy milk produced by buffalos, cows and sheep. 21 different types of pesticides were present in milk and beta-HCH was more dominant in all collected samples. Some pesticides were above the MRLs recommended by European Union [26].

In another study [27] 30 raw milk samples were collected from 28 different dairy farms in August 2007 from Spain. Extraction of raw milk samples was done by following the protocol of Pagliuca et al. [21] and analyzed through gas chromatography. The main pesticide was fenthion, detected in four samples of 12 (33.33\%), followed by dimethoate $(25 \%)$, coumaphos $(8.33 \%)$ and malathion $(8.33 \%)$. In Carbamate group, the pesticides detected were carbofuran (25\%), aldicarb $(16.67 \%)$ and carbaryl $(8.33 \%)$. In some samples, two or more active principals were detected, what explains percentages over $100 \%$. The frequency of pesticides found in this study is in agreement with Araujo et al. [28] that noted that the most pesticides commonly used in Pernambuco are from OP class, followed by $\mathrm{CB}$ and pyrethroids. The frequency of samples positive to OPPs and CB residues was lower than the one found by Nero et al. [29] that verified 196 (93.8\%) positive samples among 209 raw milk samples in four Brazilian regions. Thin Layer Chromatography, which would justify the difference in the results, since this technique presents lower specificity when compared with GC.

Pasteurized and fresh milk samples were tested for OCPs by using GC with ECD in Kampala. Aldrin, Lindane, Dieldrin, DDT and Endosulfan were detected in milk. Results showed that most of the residues detected were above the residue limits set by the FAO/WHO (2008). Bioaccumulation of these residues is likely to pose health risks to the consumers of milk in Uganda [30].

Aslam et al. planned a research to analyze the $\mathrm{OC}$ residues and their chemical composition in milk of buffalo. Milk samples were collected from Dehli. Monitoring of milk could be useful for getting information about the type and quantity of OC residues in environment and in our daily life also. The results indicated that p,p'-DDT was exceeded in $70 \%$ of milk sample, p,p'-DDE in $80 \%$ of the milk samples of in Delhi state. Dichlorodiphenyldichloroethane (DDD) another metabolite of p,p'-DDT was also present in $65 \%$ of the milk samples. The results revealed that DDT was the main contaminant in Dehli state. Endosulfan was detected in $35 \%$ milk samples. Mixture of toxic compounds present in buffalo milk samples might possibly toxic for infant's health mainly nervous system, reproductive and immune system [31].

Another study was carried out in Mexico where 40 milk samples were analyzed. It was noticed that mostly OCPs were below the MRLs adopted by Mexican regulations. However, $\mathrm{HCH}$ and Heptachlor was above the MRLs of Codex Alimentarius. It was also assessed that in future goat milk will be safer for human consumption and it is good alternative to livestock milk. Contineous monitoring for $\mathrm{HCH}$ is required through management practices [32].

In an another study, it was reported that 16 OPPs residues were determined in Tizayuca, Hidalgo, Mexico during 2008-2010. GC with ECD was used for OCPs determination and residues concentrations were found higher in wet season than dry season. Overall pesticides residues were below the MRLs proposed by Codex Alimentarius. This reduction in residues reflects that Mexican government has achieved the safety levels in response to persistent organic pollutants (POPs) agreement [33].

Ayoub and coworkers conducted a study in Egypt. They analyzed 72 buffalo milk samples for OCPs and the only detected pesticide was $\mathrm{p}, \mathrm{p}^{\prime}$ DDE. Maximum concentration was found 4.714 ppb but overall samples were below the MRLs 
recommended by Codex Alimentarius Commission (2004) [34].

In Brazil CBs and OPPs were investigated in feedstuff, water and dairy milk. GC with NPD was used to analyze these compounds. Total 30 milk samples were analyzed out of which $17 \%$ samples were contaminated with OPPS. CBs were not present in milk however, they were present in feedstuff and water samples. Same ingredient was noticed in 3 dairy farms [35].

A study was carried out to find the OCPs and OPPs residues in milk and fodder samples around the Musi river belt in India. Milk and fodder samples were collected from different six location of Musi river belt in Hyderabad, India. Collected samples were analyzed by GC with ECD for OCPs and pulsated flame photometric detector (FPD) was used for the detection of OPPs residues. Analysis of fodder showed dicofol concentration ranging from 0.071-0.077 (0.07). Dimetheoate (OPPs) was found in milk samples ranging from 0.111-0.167 (0.13). Residues of other OPPs and OCPs were below the MRLs specified by European Union (EU) and Codex. Whereas fodder dicofol and in milk dimethoate were above the MRLs values established by EU and CODEX [36]. It was reported in a study that fresh milk of buffalo collected from agro-industrial zone in upper Egypt was analyzed for OCPs and OPPs by using GC. Five different OCPs (alachlor, HCB dieldrin, methxychlor and linadane) and three different OPPs (malathion, parathion-methyl and chlorpyrifos) were identified in fresh milk samples. It was found that Malathion and Lindane exceeded permissible limit set by EU established in 2008 [37].

In addition to this, chloropyrifos, $\mathrm{HCB}$ and methoxychlor were exceeded in 33\%, 88\% and $66 \%$, respectively. However, parathion-methyl, alachlor and dieldrin were below the MRLs established by EC. Overall it was concluded that Egypt peoples are at the risk of pesticides exposure based on this, it was recommended that pesticides monitoring programs should be established in all developing countries.

Non- judicious use of pesticides leads to contamination of food commodities with pesticide residues. Although, pesticides consumption in India is $0.5 \mathrm{~kg} / \mathrm{ha}$. A survey was conducted to analyze the levels of OCPs residues in cow milk from different locations of Dhanbad city, Jharkhand, India. Milk samples were collected seasonally, and pesticide residues were assessed using gas chromatography with an electron capture detector. The results indicate that the milk samples were contaminated with DDT and its metabolites (DDE and DDD). Seasonal variations of these pesticide residue levels were also observed in all the milk samples. Samples collected during winter season were found to contain higher residue levels as compared to other seasons [38].

Ismail and Elkassas, carried out a survey to analyze the concentrations of OCPs, OPPs and Pyrethroids pesticides in milk of buffalos. The findings demonstrate that OCPs were present with high levels and their concentration exceeds the FAO/WHO and EU MRLs. OPPs detection levels were higher than MRLs established by FAO /WHO. Cypermethrin and pyrethroid concentrations were exceeded the FAO/WHO and EU limits. This survey suggests the proper monitoring of milk is required to keep consumers safe [39].

Muhammad and his co workers conducted a study in Faisalabad, where cattle milk was collected from different localities of Faisalabad, Pakistan and solid phase micro-extraction was done for pesticides residue analysis and residues were determined by using HPLC. The results of this study revealed that overall $40 \%$ samples showed pesticides contamination. The mean levels of cypermethrin, chloropyrifos, endosulphane and syhalothrin were $0.085,0.072,0.26$ and 0.38 $\mu \mathrm{g} / \mathrm{mL}$, respectively. Pesticides residues risk analysis was calculated on the bases of provisional acceptable daily intakes and analyzed pesticides residues. The daily intake levels of pesticide residues including cyhalothrin, chlorpyrifos and cypermethrin in present study were 3, 11, 2.5 times higher, respectively in cattle milk. These results showed that pesticides residues present in the milk might pose health problems in the people of this vicinity [40]. 
Pak. J. Anal. Environ. Chem. Vol. 18, No. 1 (2017)

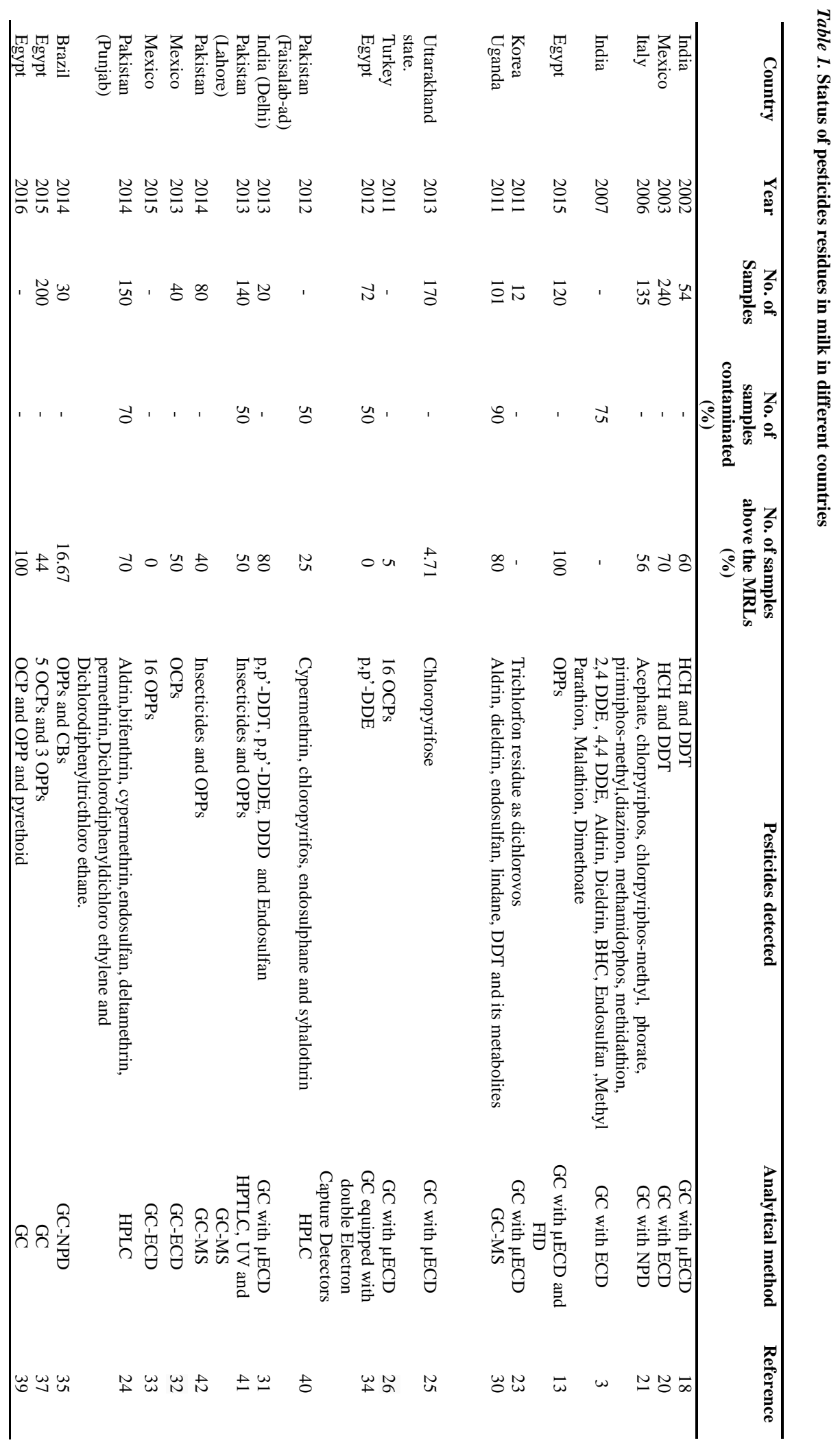


Shahzadi and her co researchers identified and quantified the insecticide imidacloprid, pyrethroid (bifenthrin, deltamethrin and lambda cyhalothrin), and OPP (chlorpyrifos) in buffalo, sheep, cow, goat and camel milk. Milk samples were collected from different locations of Lahore in Pakistan. High performance thin layer chromatography (HPTLC), Ultravioletvisible (UV) and GC-MS were used to analyze the residues contamination level. These pesticides residues were extracted with petroleum ether, ethanol and sodium oxalate. Results indicate 50 $\%$ of the milk samples were contaminated with pesticides residues. Most significantly present pesticides were Deltamethrin and maximum contamination was found in sheep milk. Milk consumption contaminated with pesticide might pose health hazardous to humans in this locality [41].

In dairy farms present in peri-urban areas, cattle are being fed on agro-industrial by products diet (cotton khal, sugarcane khal, wheat bran etc.) this activity may transfer chemicals to cattle milk. In a similar type of study [42] pyrethroid and OPPs were assessed. These pesticides when accumulated in the fat tissues and milk, they may pose adverse health risks to human's health. In the present study 30 diet and 80 milk samples were collected from different dairy farms. All the samples were processed through QuECHERS kit and analyzed by using GC coupled with mass spectroscopy. The results revealed that cypermethrin and chloropyrifos concentrations were above the MRLs in 40\% milk samples proposed by WHO. Profenofos was exceeded in the $20 \%$ milk samples.

It was reported in a research in Pakistan in which pesticides residue levels was monitored in milk of cattle from cotton growing areas of Punjab. Analyzed pesticides were aldrin, bifenthrin, cypermethrin, endosulfan, deltamethrin, permethrin, DDD and DDT. HPLC technique was used and findings showed that $70 \%$ milk samples showed exceeded level of pesticides residues. Maximum contamination was shown by Aldrin $(0.68 \mu \mathrm{g} / \mathrm{mL})$. Overall results indicated that $23 \%, 21 \%, 18 \%$ and $7 \%$ of the milk samples were contaminated with cypermethrin, bifenthrin, permethrin and detlamethrin, respectively [43].

\section{Prevention and control of pesticide residues}

Maximum residues levels (MRLs) have been set by the European Union and Codex Alimentareous to ensure that pesticides are present below the unacceptable risk limit. These MRLs are the upper legal limits of pesticides concentrations in feed and food. MRLs are established for a wide variety of plants and animal's origin based food commodities. MRLs are not simply set as threshold levels of toxicologically, but they are derived after a broad assessment of the active substance properties and their residue behavior on treated crops [44]. There was a need to investigate the pesticides residues in milk in order to provide a baseline to health department or governing bodies to make safety regulations. In addition to this, pesticides residues monitoring program is very essential for the safety of consumer health and to achieve the food safety in country.

\section{Conclusion and recommendations}

On the basis of above review worldwide including Pakistan, it is concluded that human health is associated with exposure to OCPs, OPPs and pyrethroids pesticides via milk or milk products and this issue deserve more attention. Several OPPs and OCPs pesticide residues were detected in raw animal milk samples collected from different sources in Pakistan.

The results of this review demonstrate the need to establish pesticide residue monitoring programs for milk analysis for human consumption to improve food safety and decrease exposure risks for consumers. In addition to this, these finding suggest creating awareness in owner of dairy farms and general public regarding the avoidance of pesticide residues in milk.

\section{References}

1. H. Rana, M. F. Khan, M. F. Akbar, Z. Ahmed, K. Mahmood, S. Eijaz and W. Khan, Int. J. Biol. Res, 2, (2014) 45. 
2. F. Tecles, A. Tvarijonaviciute and J. J. Cerón, Pak. Vet. J., 33 (2013) 458.

3. S. K. Nag, S. K. Mahanta, M. K. Raikwar and B. K. Bhadoria, Small Ruminant Res., 67 (2007) 235. https://doi.org/10.1016/j.smallrumres.2005. 10.008

4. A. N. Díaz and M. R. Peinado, Sens. Actuators B., 39 (1997) 426. https://doi.org/10.1016/S09254005(97)00025-7

5. K. C. Jones and P. De Voogt, Environ. Pollut., 100 (1999) 209. https://doi.org/10.1016/S02697491(99)00098-6

6. P. Stefanelli, A. Santilio, L. Cataldi and R. Dommarco, J. Environ. Sci. Health B, 44 (2009) 350.

https://doi.org/10.1080/0360123090280100 $\underline{0}$

7. S. Tao, W. X. Liu, X. Q. Li, D. X. Zhou, X. Li, Y. F. Yang R. M. Coveney, Environ. Pollut., 157 (2009) 497.

https://doi.org/10.1016/j.envpol.2008.09.00 $\underline{5}$

8. S. Muralidharan, V. Dhananjayan and P. Jayanthi, Environ. Res., 109 (2009) 15. https://doi.org/10.1016/j.envres.2008.08.00 $\underline{6}$

9. M. LeDoux, J. Chromatogr. A, 1218 (2011) 1021.

https://doi.org/10.1016/j.chroma.2010.12.0 97

10. L. Alder, K. Greulich, G. Kempe and B. Vieth, Mass Spectrom. Rev., 25 (2006) 838. https://doi.org/10.1002/mas.20091

11. S. J. Lehotay, K. Maštovská and S. J. Yun, J. AOAC Int., 88 (2005) 630.

12. J. Falandysz, B. Wyrzykowska, J. Warzocha, I. Barska, A. GarbacikWesołowska and P. Szefer, Food Chem., 87 (2004) 17.

https://doi.org/10.1016/j.foodchem.2003.10 .011

13. E. M. Shaker and E. E. Elsharkawy, Environ. Toxicol. Pharmacol., 39 (2015) 433. https://doi.org/10.1016/j.etap.2014.12.005

14. I. Baranowska, H. Barchańska and E. Pacak, Environ. Pollut., 143 (2006) 206. https://doi.org/10.1016/j.envpol.2005.11.03 $\underline{9}$

15. M. Fontcuberta, J. F. Arqués, J. R. Villalbi, M. Martínez, F. Centrich, E. Serrahima and C. Casas, Sci. Total Environ., 389 (2008) 52.

https://doi.org/10.1016/j.scitotenv.2007.08. $\underline{043}$

16. E. Kampire, B. T. Kiremire, S. A. Nyanzi, and M. Kishimba, Chemosphere, 84 (2011) 923.

https://doi.org/10.1016/j.chemosphere.2011 .06 .011

17. K. Borgå, G. W. Gabrielsen, J. U. Skaare, Environ. Pollut., $113 \quad$ (2001) 187. https://doi.org/10.1016/S02697491(00)00171-8

18. G. G. Pandit, S. Sharma, P. K. Srivastava, and S. K. Sahu, Food Addit. Contam. 19 (2002) 153.

https://doi.org/10.1080/0265203011008115 $\underline{5}$

19. H. Dahshan, A. M. Megahed,A. M M. Abd-Elall, M. A. G. Abd-El-Kader, E. Nabawy \& M. H. Elbana. J. Environ. Health Sci. Eng., 14 (2016) 15. https://doi.org/10.1186/s40201-016-0259-6

20. V. T. Pardio, K. N. Waliszewski, L. A. Landin and R. G. Bautista, Food Addit. Contam. A, 20 (2003) 259. https://doi.org/10.1080/0265203021000046 $\underline{207}$

21. G. Pagliuca, A. Serraino, T. Gazzotti, E. Zironi, A. Borsari and R. Rosmini, $J$. Dairy Res., 73 (2006) 340. https://doi.org/10.1017/S002202990600169 $\underline{5}$

22. J. Weber, C. J. Halsall, D. Muir, C. Teixeira, J. Small, K. Solomon and T. Bidleman, Sci. Total Environ., 408, (2010) 2966. https://doi.org/10.1016/j.scitotenv.2009.10. $\underline{077}$

23. M. LeDoux, J. Chromatogr. A, 1218, (2011) 1021. https://doi.org/10.1016/j.chroma.2010.12.0 97

24. A. Ul Hassan, A. B. Tabinda, M. Abbas and A. M. Khan, Pak. J. Agri. Sci., 51 (2014) 321. 
25. N. S. Karabasanavar and S. P. Singh, Int. J. Dairy Technol., 66, (2013) 189. https://doi.org/10.1111/1471-0307.12007

26. S. Bulut, L. Akkaya, V. Gök and M. Konuk, Environ. Monit. Assess. 181, (2011) 555.

https://doi.org/10.1007/s10661-010-1849-x

27. F. Rafael, B. Vanerli, P. P. Ana, D. Karen, and T. Ronaldo, Pesq. Vet. Bras. 31 (2011) 598.

https://doi.org/10.1590/S0100736X2011000700009

28. A. C. Araújo, D. P. Nogueira, and L.G. Augusto, Revista de Saúde Pública, 34, (2000) 309.

https://doi.org/10.1590/S0034-

$\underline{89102000000300016}$

29. L. A. Nero, M. R. Mattos, V. Beloti, M. A.

F. Barros, D. P. Netto and B. D. G. Franco de M. Ciênc. Tecnol. Aliment. 27, 201 (2007).

https://doi.org/10.1590/S010120612007000100035

30. E. Kampire, B. T. Kiremire, S. A. Nyanzi and M. Kishimba, Chemosphere, 84, (2011) 923.

https://doi.org/10.1016/j.chemosphere.2011 .06 .011

31. M. Aslam, S. Rais and M. Alam, $J$. Environ. Prot., 4 (2013) 964. https://doi.org/10.4236/jep.2013.49111

32. B. Schettino, R. Gutiérrez, R. Ortiz, S. Vega, G. Urban, A. Ramírez, Bull. Environ. Contam. Toxicol., $91 \quad$ (2013) 154. https://doi.org/10.1007/s00128-013-1005-8

33. R. Gutiérrez, S. Vega, R. Ortiz, J. J. Pérez, and B. Schettino. J. Environ. Sci. Health B., 50 (2015) 317.

https://doi.org/10.1080/03601234.2015.100 $\underline{0166}$
34. M. M. Ayoub, M. E. Desoki, A. S. Hassanin, W. M. Thabet, M. H. Mansour, Nagwa M. Loutfy and A. Raslan, J. Plant Prot. Path., 3 (2012) 865.

35. Da Silva, LCC, V. Beloti, R. Tamanini and D. P. Netto, Agrarian Sciences, Londrin., 35 (2014) 2485.

36. K. Kotinagu and N. Krishnaiah, Vet. World, 8 (2015) 545. https://doi.org/10.14202/vetworld.2015.545 $\underline{-550}$

37. E. M. Shaker and E. E. Elsharkawy, Environ. Toxicol. Pharmacol., 39 (2015) 433.

https://doi.org/10.1016/j.etap.2014.12.005

38. R. M. Barman, B. K. Mishra and A. Barman. Int. J. Appl. Pure Sci. Agri. 02 (2016) 1.

39. T. Ismail and W. M. Elkassas, Alexandria J. Vet. Sci., 48 (2016) 113.

40. F. Muhammad, I. Javed, M. Akhtar, M. M. Awais, M. K. Saleemi and M. I. Anwar, Pak. Vet. J., 10 (2012) 4.

41. N. Shahzadi, M. Imran, M. Sarwar, A. S. Hashmi and M. Wasim, J. Agroaliment. Proc. Technol., 19 (2013) 167.

42. B. Iftikhar, S. Siddiqui and S. Rehman, Afr. J. Biotechnol., 13 (2014).

43. A. ul Hassan, A. B. Tabinda, M. Abbas and A. M. Khan, Pak. J. Agric. Sci., 51 (2014) 321.

44. M. LeDoux, J. Chromatog. A, 1218 (2011) 1021. 